\title{
Flowers and thorns in pregnancy: experiences during the COVID-19 pandemic
}

\section{Maíra Rossetto ${ }^{a}$ \\ Jeane Barros de Souzab \\ Graciela Soares Fonsêca ${ }^{a}$ \\ Vanessa Vitória Kerkhoff ${ }^{\mathrm{a}}$ \\ Juliana Romanoski Alves e Mourab}

\begin{abstract}
How to cite this article: Rossetto M, Souza JB, Fonsêca GS, KerkhoffVV, Moura JRA. Flowers and thorns in pregnancy: experiences during the COVID-19 pandemic. Rev Gaúcha Enferm. 2021;42:e20200468. doi: https://doi.org/10.1590/19831447.2021.20200468
\end{abstract}

Universidade Federal da Fronteira Sul (UFFS) Curso de Graduação em Medicina. Chapecó, Santa Catarina, Brasil.

' Universidade Federal da Fronteira Sul (UFFS), Curso de Graduação em Enfermagem. Chapecó, Santa Catarina, Brasil.

\section{ABSTRACT}

Objective: To understand the repercussions of COVID-19 on the path of pregnancy.

Method: Qualitative, participatory action research (PAR) study, based on Paulo Freire's Research Itinerary. A virtual culture circle was held in October 2020, with the participation of 12 pregnant women, living in the South and Southeast regions of Brazil.

Results: In the virtual culture circle, pregnant women talked and critically reflected on two generating themes: flowers and thorns in the course of pregnancy. They meant living in the virtual culture circle as spaces for sharing experiences, welcoming and learning, among others.

Conclusions: For the participants, pregnancy during the pandemic brought difficulties such as social isolation, absence from work and the university, fears, anxieties, loneliness and insecurities. However, it also improved health care, intensifying self-care and investment in family relationships.

Keywords: Pregnancy. Coronavirus infections. Adaptations, psychological. Pandemics. Women's health.

\section{RESUM0}

Objetivo: Compreender as repercussões da COVID- 19 no caminho da gestação.

Método: Estudo qualitativo, do tipo ação-participante, com fundamentação no Itinerário de Pesquisa de Paulo Freire. Realizou-se um círculo de cultura virtual em outubro de 2020, com a participação de 12 gestantes, residentes nas regiões Sul e Sudeste do Brasil. Resultados: No círculo de cultura virtual, as gestantes dialogaram e refletiram criticamente sobre dois temas geradores: flores e espinhos no caminhar da gestação. Significaram a vivência no círculo de cultura virtual como espaços para compartilhar experiências, acolhimento e aprendizado, dentre outros

Conclusões: Para as participantes, a gestação durante a pandemia trouxe dificuldades como isolamento social, afastamento do trabalho e da universidade, medos, angústias, solidão e inseguranças. Mas, também, melhorou os cuidados com a saúde, intensificando 0 autocuidado e 0 investimento nas relações familiares.

Palavras-chave: Gravidez. Infecções por Coronavírus. Adaptação psicológica. Pandemias. Saúde da mulher.

\section{RESUMEN}

Objetivo: Comprender las repercusiones del COVID-19 en la trayectoria del embarazo

Método: Estudio cualitativo, acción-participante, basado en el Itinerario de Investigación de Paulo Freire. En octubre de 2020 se realizó un círculo de cultura virtual, con la participación de 12 mujeres embarazadas, residentes en las regiones Sur y Sudeste de Brasil. Resultados: En el círculo de cultura virtual, las gestantes dialogaron y reflexionaron críticamente sobre dos temas generadores: flores y espinas en el transcurso del embarazo. Significaron vivir en el círculo de cultura virtual como espacios para compartir experiencias, acoger y aprender, entre otros.

Conclusiones: Para las participantes, el embarazo durante la pandemia trajo dificultades como aislamiento social, ausencia del trabajo y de la universidad, miedos, ansiedades, soledad e inseguridades. Pero también mejoró la atención médica, intensificando el autocuidado e invirtiendo en las relaciones familiares.

Palavras clave: Embarazo. Infecciones por Coronavirus. Adaptación psicológica. Pandemias. Salud de la mujer. 


\section{口INTRODUCTION}

The Coronavirus Disease 2019 (COVID-19) pandemic, caused by the Severe Acute Respiratory Syndrome Coronavirus 2 (SARS-CoV-2), emerged in late 2019 in Wuhan, China (1). The virus spread quickly, causing an abrupt increase in the number of infected people and deaths ${ }^{(2)}$.

In the context of the pandemic, associations between COVID-19 and the vulnerability of some risk groups, who have higher mortality rates, were soon identified ${ }^{(1)}$. Pregnant women are included in the high-risk groups for the disease because physiological changes in the woman's body make them more vulnerable to serious infections ${ }^{(3)}$. Women with high-risk pregnancies (i.e. with complications such as hypertension, diabetes or obesity) deserve special attention, as they may experience a more severe COVID-19 disease progression compared to pregnant women not affected by such comorbidities ${ }^{(4)}$. In Brazil, according to the guidelines of the Ministry of Health, all pregnant and postpartum women up to 14 days postpartum are considered a risk group for COVID-19(4).

In view of the greater risks of complications and maternal deaths, especially in the last trimester of pregnancy and in the postpartum period ${ }^{(5)}$, social isolation is the best form of prevention. However, pregnant women may experience several emotions, which impact their mode of self-care and experience of pregnancy. Given the unique circumstances of the pandemic, the following research question was formulated: what are the perceptions of pregnant women about the COVID-19 pandemic during pregnancy?

Due to the restrictions imposed by social isolation and its implications for the mother-baby binomial, women need to be heard. Pregnant women are a vulnerable population in the face of COVID-19, which should deserve greater attention from nurses and other health professionals. Moreover, it is essential to reflect on the feelings that influence the course of pregnancy during the pandemic, as this is a recent situation and can be experienced in different ways by women. Thus, the general objective of this study was to understand the effects of COVID-19 during pregnancy.

\section{METHOD}

This is a qualitative, participatory action research (PAR) study ${ }^{(6)}$ based on Paulo Freire's concepts. In this study, Paulo Freire's Research Itinerary composed of three dialectical and interdisciplinary phases, namely: thematic research; encoding and decoding; and critical unveiling was investigated ${ }^{(7)}$.

The Research Itinerary was developed in the Virtual Culture Circle (VCC), a space where people with some common interests talk and reflect on their reality, in order to build a deeper and expanded perception of their life status( ${ }^{(7)}$. The research itinerary was developed in the Virtual Culture Circle (VCC), a space in which people who have common interests talk and reflect on their reality, in order to build a deeper and expanded perception of their lives ${ }^{(7)}$. However, given the need for social isolation imposed by the Covid-19 pandemic, the culture circle was carried out virtually. For this, the Google Meet application was used, with the support of electronic devices, which made it possible the integration of all participants. A guide on topics that should be addressed during the VCC was prepared for data collection.

Twelve pregnant women who lived in different locations in the South and Southeast regions of Brazil participated in the study. First, three pregnant women from social networks were invited by telephone to participate in the survey. Then, snowball sampling ${ }^{(8)}$ was used, that is, the first three participants recruited future subjects to integrate the VCC. Women with psychological and emotional disorders that made their participation in the study impossible were excluded. Eighteen pregnant women were invited, but only 12 were willing to participate in the research. Pregnant women and researchers participated in data collection.

In the week prior to the VCC, the study participants received a message, via internet messaging application, explaining the objective of the research and the need to sign the Informed Consent Form (FICF). The ICF was sent to the women, who signed it and returned it to the researchers. The participants were also instructed on how to access the application, and their doubts were clarified.

A VCC lasting approximately two hours was developed on October 14,2020. On the day of data collection, the participants and researchers were at their homes and contact was only virtual. The VCC was mediated by the researchers, who used a field diary for the records. The meeting was recorded, with the permission of the pregnant women. For an interactive, creative and more concrete traveling of the phases of Paulo Freire's Research Itinerary, an analogy was made with the pregnant woman walking a path, as shown in Figure 1.

In the Thematic Investigation stage, the VCC mediator reflected on the path taken by pregnant women during the pandemic experience and launched the following question: what are the effects of the COVID-19 pandemic on the path of your pregnancy? Listening to background music, the participants were invited to answer the researcher's question by writing a representative word on a sheet of paper. The participants expressed their words and explained their meanings, while a researcher recorded the words. The records were presented on a shared screen for all pregnant women, 
so that they validate this data. The women read and re-read the words together, to organize and select the themes that generated the discussion, and two themes finally emerged: 1) Flowers in the course of pregnancy:2) Thorns in the course of pregnancy. In this metaphor, the flowers represent the positive aspects and the thorns allude to the challenges experienced by pregnant women.

To go through the Coding and Decoding of the Research Itinerary, the mediator posed the following questions: what are the flowers and what are the thorns in the course of your pregnancy? Thus, again while listening to background music, the participants were asked by the mediator to reflect on the question and answer it. Then, the pregnant women exposed their perceptions, talking and reflecting freely and critically, about the experience of pregnancy during the COVID-19 pandemic, with substantial exchange of knowledge.

While the pregnant women verbalized their perceptions, the mediator recorded the words on the screen shared with all pregnant women. Thus, all participants were able to see the records, and each generating theme was discussed separately, as shown in Figure 2. No software was used for data synthesis.

Then, the mediator read all the notes, seeking to re-signify the dialogues that emerged during the VCC. Then Critical Unveiling, the third phase of Paulo Freire's Research Itinerary began and so the mediator highlighted the learnings and meanings shared by the participants when they unveiled their limits and possibilities in the course of pregnancy in pandemic times. They reflected on the need to keep the thorns away during pregnancy, recognizing the presence of flowers in the process of coping with the COVID-19 pandemic, raising awareness and mutually strengthening each other. At the end of the activity, the mediator encouraged the pregnant women to reflect on the meaning of their participation in the VCC.

The dialogues were transcribed and organized into digital folders, according to the two generating themes that emerged during the VCC. For data analysis, the information contained in these folders was carefully read. Data analysis (themes) was performed concomitantly with the development of the VCC, according to Freire's Itinerary ${ }^{(7)}$.

The study was conducted by the researchers, all women, as follows: a doctor and professor, a PhD holder and professor in Nursing, a medical doctor doctor and professor in collective health, an undergraduate student in Nursing and a medical graduate student. The authors were not previously acquainted with the participants: the first contact was made through the social networks, and snowball sampling was used to recruit the other participants. Thus, before the VCC, the pregnant

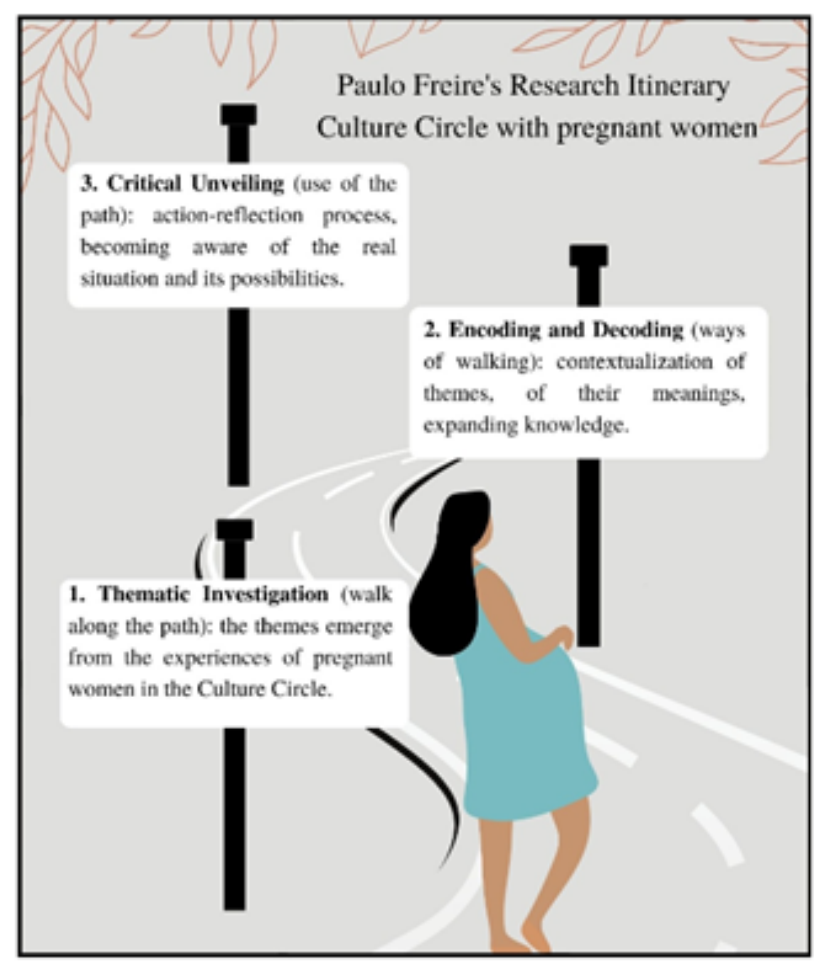

Figure 1 - Paulo Freire's Research Itinerary: analogy with a pregnant woman's path

Source: Elaborated and adapted by the authors from the concepts proposed by the authors ${ }^{(7)}$.

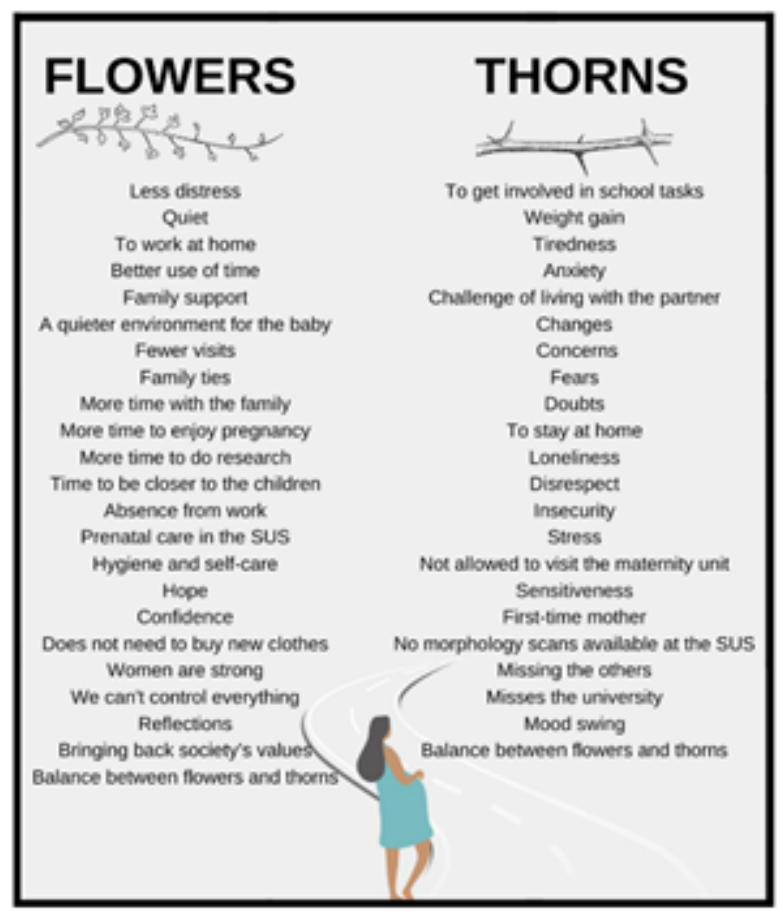

Figure 2 - Representation of encodings and generating themes unveiled in the Virtual Culture Circle Source: Elaborated by the authors based on the VCC dialogues, 2020. 
women had not been informed about the objectives of the study or about the issues that would be addressed by the researchers during the VCC.

The study was carried out in accordance with the principles of Resolution no 466, of 2012. Study participants were coded with flower names in order to preserve their anonymity. The study was approved by the Research Ethics Committee (CEP) with human beings from a public university in southern Brazil, under protocol number 4,068,387, on June 3, 2020.

\section{DESULTS}

The participants were pregnant women, with a gestational age of 15-38 weeks. They lived in the South and Southeast regions of Brazil, 11 from Santa Catarina and one from São Paulo, aged between 22 and 38 years old. Regarding marital status, eight were married, two were in a stable relationship and two were single. They had the following occupations: executive, shoe preparer, assembly assistant, controllership analyst, student, manager, sector assistant at a shoe factory, civil servant, nutritionist, teacher, lawyer and tour operator.

In the discussion of the first generating theme, in which they talked about flowers in the course of pregnancy, the participants emphasized that they managed to work at home due to the need for social isolation imposed by COVID-19 pandemic. Some women were allowed to stay at home. Therefore, they had more time to focus on their pregnancy and be closer to their family members, as well as obtain more information about this important period of their lives:

I was told to stay at home because of the pandemics and this was good because I had more time to enjoy my pregnancy. (Gerbera)

Thanks to the pandemic, we have more time to spend with our families. (Rose)

I had more time to seek information related to pregnancy because of Covid-19. (Violet)

The women also mentioned that they had the opportunity to be closer to their children, watching them learn and grow, making a better use of their time and expanding family ties. According to them, with the pandemic, the society is bringing back some important values and reflecting on the future of humanity.
Because of the pandemic, I have now the privilege to be closer to my children. (Hydrangea)

My family is united and our bonds have grown stronger. (Jasmine)

This pandemic has made the world reflect on the future of humanity and that is very good. (Amaryllis)

As a positive factor in the course of pregnancy in pandemic times, the women also mentioned feelings of hope, confidence, a quieter environment for the newborn babies, as there will be fewer visits due to social isolation and the importance of family support in the pregnancy process:

I'm feeling pretty calm. (Azalea)

I believe that everything will work out fine. (Begonia)

I feel confident and safer now. (Marigold)

Because of this pandemic, we will have more peace of mind. (Violet)

With the pandemic, we will have fewervisits to our babies, and this turns out to be good. (May flower)

I realize the importance of having the support of my family during this period. (Rose)

The pregnant women talked about recovering the importance of everyday hygiene and self-care habits and emphasized the fact that they do not need to buy new clothes as a positive aspect:

The pandemic brought to light the importance of practicing hygiene habits and that everyone needs to take better care of themselves, and that was a good thing. (Gerbera)

Another good thing was that we didn't feel the need to buy new clothes because we spend most time at home, and so we save money. (Violet)

They praised the care provided by the Unified Health System (SUS) during prenatal care, stating that women are strong and need to recognize that not everything can be controlled:

I was very satisfied with the care I received at SUS throughout my prenatal care. (Daisy)

Women are very strong. We are able to overcome our obstacles and we will overcome all that too. (Amaryllis) I try to accept that I can't do everything, that not everything depends on me, because we can't control everything. (Begonia) 
The pregnant women demonstrated the need to bring balance to their lives, i.e. balancing flowers and thorns in facing the COVID-19 pandemic:

We must be reasonable, achieving a good life balance, by recognizing the flowers and keeping the thorns away. (Rose)

When talking about the second generating theme, when they reflected on the thorns in the path of pregnancy in coping with the COVID-19 pandemic, the participants highlighted feelings of loneliness, fear, concerns, anxiety and insecurity:

I feel very lonely at home because my husband goes to work and I stay home alone. (May's flower)

I'm afraid of getting this disease when I leave home for my prenatal exams or during the appointments. (Daisy)

I worry about the future and that makes me feel very insecure. (Violet)

Ifeel very anxious and this is difficult to control. (Marigold)

I think there is a general feeling of insecurity because of all the situations we've been facing. (China Pink)

Another difficulty pointed out by the women was the need to stay at home, added to the fact of being responsible for the children's school tasks, which results in tiredness, weight gain, stress, and the women miss their loved ones and going to university:

I don't like having to stay at home as I go out a lot. (Rose) I get tired of being involved in my son's school tasks and that stresses me out a lot. (Jasmine)

I feel very tired. (Hydrangea)

I'm gaining weight because at home we eat all the time and eat more than we should too. (Amaryllis)

Wegetstressed witheverythingthatishappening. (Begonia)

I miss being with my family, talking to them more, and now we can't get together like we used to. (Marigold)

I miss going to college to study. (Amaryllis)

The changes in the lives of these pregnant women and in the world around them raised doubts, especially for primiparous women, who became more sensitive and had mood swings:

I have many doubts about the real risks of having COVID-19 during pregnancy. (Gerbera)
We, first-time mothers, have many doubts. (Hydrangea)

My nerves are on edge. (Daisy)

I experience mood swings and that is not good for me. (Azalea)

One pregnant woman addressed the challenges of living with her partner, because they had been living together for a short time, and others mentioned problems related to SUS care:

I find it difficult for us to face this situation in the beginning of a relationship, it is not easy. (Jasmine)

I felt disrespected when I went to get my Covid-19 vaccine at the health unit and that made me sad, I didn't like it. (Violet)

So far, I haven't managed to have a morphology scan performed, because the health center has not authorized it. (Gerbera)

I want to know the maternity unit of the hospital where I will have my baby, but they don't let us in there, they are limiting the visits. (Daisy)

Asked about the meanings of participating in the VCC, the pregnant women said it was a special moment of sharing experiences, which provided learning, welcoming, dialogue, pleasure and good feelings, as seen in Figure 3.

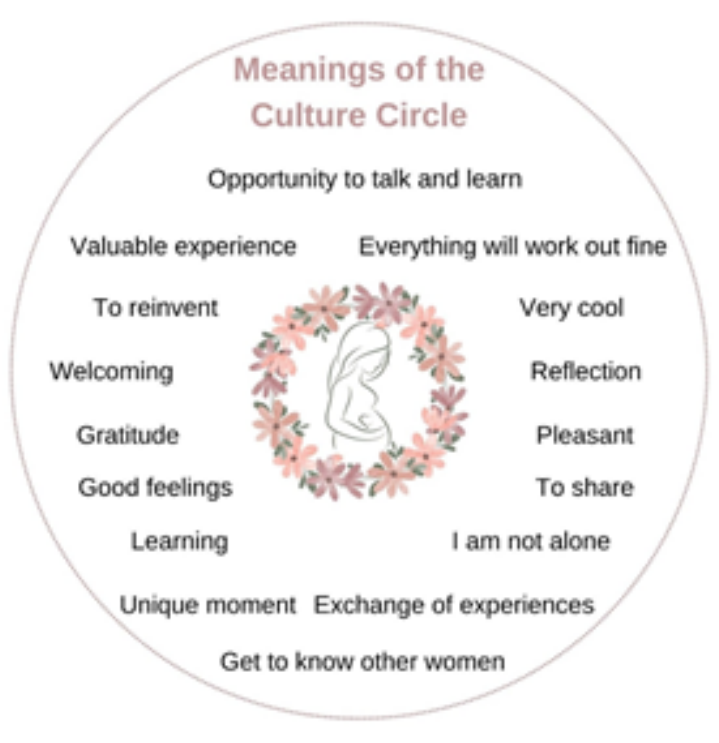

Figure 3 - Meanings of pregnant women in experiencing the Virtual Culture Circle

Source: Adapted by the authors from https://br.pinterest.com/pin/842384305279444945/ 


\section{DISCUSSION}

COVID-19 has raised different feelings and created numerous barriers, especially for pregnant women, during the course of pregnancy, due to restrictions on leaving the house and doing routine activities, going to work and attending health services for prenatal care. There have been situations of emotional instability and insecurity about the future, which can increase anxiety and uncertainty related to pregnancy and childbirth ${ }^{(9)}$.

Pregnancy requires adaptation to something new and promotes several changes in the women's bodies, as well as mood swings, weight gain, with impact on family relationships and in the ways of social interaction ${ }^{(10)}$. Different actions taken by the families, the women and the health care services are necessary to promote an adequate welcoming of pregnant women and their babies. Thus, many pregnant women experience anxiety and mood swings, a situation that worsens during the pandemic, as the occurrence of COVID-19 raised more doubts and concerns, such as fear of contagion and greater insecurity about the future ${ }^{(11)}$.

Furthermore, adherence to social isolation is related to the fear of contracting the infection and transmitting it to the fetus, and when social isolation is not a harmonious process, it may become a risk predictor for psychological conditions, which can trigger stress, anger, distress and a feeling of isolation from the rest of the world ${ }^{(12)}$. Despite the need for social isolation in this pandemic period, pregnant women must remain active and plan for the future. In this regard, greater psychological support should be ensured to these women during the pandemic, with the offer of multidisciplinary care, combined with proper nutrition, sleep, rest and leisure activities ${ }^{(11)}$.

The women reported anxiety because of their concern about the possible effects of COVID-19 on their babies' development, as well as due to the lack of vaccines and tests in pregnant women ${ }^{(13)}$. Therefore, further studies on the subject are needed, as there is insufficient evidence on the greater severity of Covid-19 for pregnant women and the occurrence of intrauterine transmission ${ }^{(14)}$.

Due to social isolation, the women had to adapt to new routines and ways of relating to their families. Some pregnant women, who had other children and reported the challenges of living with teenagers and getting involved with school tasks, had to devote more time to their children due to the use of the internet and online classes ${ }^{(15)}$.

In times like these, when we face difficult situations and miss family members, the support of other people, who experience the same situations, can be a strategy for assistance and care. Pregnant women's groups are frequent strategies in
Primary Health Care $(\mathrm{PHC})^{(16)}$, but they are suspended during the pandemic. Thus, educational groups can be conducted online, and they are a low-cost tool that can be widely used in health prevention and promotion actions ${ }^{(17)}$.

Regarding the thorns in the course of pregnancy, it was evident that women learn from adversity and re-signify existing values and family ties, relying on positive feelings of hope, confidence, strength and courage to face the challenges. They are aware of their strength and seek to overcome the challenges of motherhood, whether for the first time or in a new pregnancy.

These feelings were reported by the participants, and they are a positive link with the future, a rupture of what is not possible now, but could be possible in the future ${ }^{(18)}$. This strategy seeks coping and resilience in the face of adversity, in a balanced way to face adversity, so that babies are born healthy.

The new home office routine has made it possible to reorganize time, and pregnant women can spend more time with their children and relatives, prepare themselves for the new babies and obtain more information about pregnancy. Thus, they can feel calm during pregnancy and reduce stress levels ${ }^{(10)}$. As pregnant women spend more time at home, they do not need new clothes and can save money. This has a positive economic impact, as some of these women had their incomes reduced during the pandemic.

Social isolation is providing women with another way of experiencing the postpartum period, due to the recommendations to limit the number of visitors to the newborn babies and postpartum women and encouragement to the adoption of healthy habits such as the use of alcohol gel and masks ${ }^{(4)}$. All these measures are considered positive by pregnant women, as other diseases, in addition to COVID-19, can be transmitted to the newborns ${ }^{(10)}$.

Thus, testing for diseases and prenatal care in the SUS were reported by the women as being positive, as there was greater availability to schedule appointments and exams at health units, providing an opportunity for prompt assistance, as recommended by the Ministry of Health ${ }^{(4)}$. Nevertheless, one participant reported difficulty in understanding the regulations, because the health professionals who assisted her were unaware of them, which resulted in lack of respect and dissatisfaction. Pregnant women should be assisted in PHC and are entitled to six prenatal consultations and one consultation in the postpartum period, with classification of gestational risk, and referral to reference services, when recommended ${ }^{(12)}$. During the pandemic, there is no indication or prohibition of the presence of a companion of the pregnant woman's choice during consultations, exams, childbirth and hospitalization ${ }^{(5)}$. 
Due to social isolation, new means of communication between professionals and pregnant women and online support were needed. To reduce the risks to pregnant and postpartum women, the Ministry of Health suggests the use of teleconsultations and scheduled appointments and exams, for an adequate control of risk factors in pregnancy ${ }^{(18)}$. Therefore, the use of different technologies and applications can maximize nursing care and reduce the response time to a possible adversity.

An important innovation of this study is the use of participatory research, which is successful because it combines exchange of knowledge and mutual learning. It is a low-cost research and can involve people in different locations, resulting in greater interest of women in their prenatal care. Nursing can act in this scenario by encouraging self-care measures, prevention and health promotion during pregnancy and the postpartum period ${ }^{(19)}$ Nursing professionals, in the roles of educators, managers and care providers, gained greater visibility during the pandemic. They listen to the families and understand that humanistic competence cannot be dissociated from ethical-political competence and the pedagogical role of nursing practice ${ }^{(20)}$.

Thus, the VCC is an important tool for Nursing regarding the development of studies and the promotion of health in pandemic times, enabling full care, although only virtual now, targeted mainly to groups at risk for COVID-19, such as pregnant women. These groups are a strategy frequently used in PHC and provide an excellent opportunity to promote health and clarify women's doubts. The VCCs can assist in this exchange of experiences and mutual strengthening ${ }^{(16)}$.

A limitation of this study was the lack of time available to talk to pregnant women about measures to deal with the pandemic in this cultural circle. It is suggested, then, that this be addressed in future studies. At the end of the activity, the participants requested a new online meeting, stating that this is a special moment for exchanging experiences and developing bonds with other pregnant women. Thus, the importance of carrying out new VCCs during the pandemic with other pregnant women and with various populations from other regions of Brazil is reaffirmed here, to allow mutual learning, a space for reflection and active listening.

\section{口INAL CONSIDERATIONS}

In the VCC, the pregnant women were given some time to reflect on their pregnancy and how to walk along this path. The effects of the pandemic on pregnancy were both positive and negative, and the women said it was valuable to realize that social isolation imposed several restrictions on living, brought challenges, fears and anxieties, but also motivated women to self-care, provided greater contact with family members and more time for them to get prepared for their babies. The women reflected on the pandemic, realizing that in the course of pregnancy, the flowers and thorns allowed them to change their walk, and they often needed serenity and balance to understand that they cannot control everything.

The importance of conducting a qualitative research with pregnant women should be emphasized, as this study made it possible to understand how the pandemic impacts their path during pregnancy. The context of social isolation often makes it impossible for researchers to contact the women and understand how this group is facing social isolation, as well as the other effects of the pandemic on pregnancy.

The VCC, based on Paulo Freire's theoretical reference, allowed a virtual meeting for the sharing of experiences, qualified listening and mutual learning. The use of the VCC as a methodological instrument in the field of research is innovative in Nursing and can provide for the development of various activities during the pandemic, in a responsive, creative and human way, providing welcoming, autonomy and empowerment of the subjects.

The pandemic context requires professionals to adapt themselves to the assistance of pregnant women, whether in care, education or management. The VCC can help nursing professionals, as it allows talking, identifying problems, listening and proposing solutions in a context of social isolation.

\section{REFERENCES}

1. Ahmad AR, Murad HR. The impact of social media on panic during the COVID-19 pandemic in iraqi Kurdistan: online questionnaire study. J Med Internet Res. 2020;22(5):e19556. doi: https://doi.org/10.2196/19556

2. Zhu N, Zhang D, Wang W, Li X, Yang B, Song J, et al. A novel Coronavirus from patients with pneumonia in China, 2019. N Engl J Med. 2020;382(8):727-33. doi: https://doi.org/10.1056/NEJMoa2001017

3. Favre G, Pomar L, Musso D, Baud D. 2019-nCoV epidemic: what about pregnancies? Lancet. 2020;395(10224):e40. doi: https://doi.org/10.1016/ S0140-6736(20)30311-1

4. Ministério da Saúde (BR). Secretaria de Atenção Primária à Saúde. Manual de recomendações para a assistência à gestante e puérpera frente à pandemia de Covid-19. Brasília (DF): Ministério da Saúde; 2020 [cited 2020 0ct 15]. Available from: http://189.28.128.100/dab/docs/portaldab/documentos/corona/ manual_recomendacoes_gestantes_covid19.pdf

5. Rasmussen SA, Smulian JC, Lednicky JA, Wen TS, Jamieson DJ. Coronavirus Disease 2019 (COVID-19) and pregnancy: what obstetricians need to know. Am J Obstet Gynecol. 2020;222(5):415-26. doi: https://doi.org/10.1016/j.ajog.2020.02.017

6. Moraes RCP, Anhas DM, Mendes R, Frutuoso MFP, Rosa KRM, Silva CRC. Pesquisa participante na estratégia saúde da família em territórios vulneráveis: a formação coletiva no diálogo pesquisador e colaborador. Trab Educ Saúde. 2017;15(1):20522.doi: https://doi.org/10.1590/1981-7746-sol00035 
7. Heidemann ITSB, Dalmolin IS, Rumor PCF, Cypriano CC, Costa MFBNA, Durand MK. Reflections on Paulo Freire's research itinerary: contributions to health. Texto Contexto Enferm. 2017;26(4):e0680017. doi: http://doi. org/10.1590/0104-07072017000680017

8. Naderifar M, Goli H, Ghaljaie F. Snowball sampling: a purposeful method of sampling in qualitative research. Strides Dev Med Educ. 2017;14(3):e67670. doi: https://doi.org/10.5812/sdme.67670

9. Dickinson F, McCauley M, Smith H, Broek ND. Patient reported outcome measures for use in pregnancy and childbirth: a systematic review. BMC Pregnancy Childbirth. 2019;19:155. doi: https://doi.org/10.1186/s12884-019-2318-3

10. Ministério da Saúde (BR). Secretaria de Atenção à Saúde. Departamento de Atenção Básica. Atenção ao pré-natal de baixo risco. Brasília (DF): Ministério da Saúde; 2012 [cited 2020 0ct 19]. Cadernos de Atenção Básica, n. 32. Available from: http:// bvsms.saude.gov.br/bvs/publicacoes/cadernos_atencao_basica_32_prenatal.pdf

11. Mascarenhas VHA, Caroci-Becker A, Venâncio KCMP, Baraldi NG, Durkin AC, Riesco MLG. COVID-19 and the production of knowledge regarding recommendations during pregnancy: a scoping review. Rev Latino-Am Enfermagem. 2020;28:e3348. doi: http://doi.org/10.1590/1518-8345.4523.3348

12. Bezerra ACV, Silva CEM, Soares FRG, Silva JAM. Factors associated with people's behavior in social isolation during the COVID-19 pandemic. Ciênc Saúde Coletiva. 2020;25(Suppl 1):2411-21. doi: https://doi. org/10.1590/1413-81232020256.1.10792020

13. Mascarenhas VHA, Caroci-Becker A, Venâncio KCMP, Baraldi NG, Durkin AC, Riesco MLG. Care recommendations for parturient and postpartum women and newborns during the COVID-19 pandemic: a scoping review. Rev Latino-Am Enfermagem. 2020;28:e3359. doi: http://doi.org/10.1590/1518-8345.4596.3359
14. Gonçalves AK. The real impact of the Coronavírus Disease 2019 (covid-19) on the pregnancy outcome [letter]. Rev Bras Ginecol Obstet. 2020;42(5):303-4. doi: http://doi.org/10.1055/s-0040-1712942

15. Deslandes SF, Coutinho T. The intensive use of the internet by children and adolescents in the context of COVID-19 and the risks for self-inflicted violence. Ciênc Saúde Coletiva. 2020; 25(Suppl 1):2479-86. doi: https://doi. org/10.1590/1413-81232020256.1.11472020

16. Domingues F, Pinto FS, Pereira VM. Grupo de gestantes na atenção básica: espaço para construção do conhecimento e experiências na gestação. Rev Fac Ciênc Méd Sorocaba. 2018;20(3):150-4 doi: https://doi. org/10.23925/1984-4840.2018v20i3a6

17. Bermejo-Sánchez FR, Peña-AyudanteWR, Espinoza-Portilla E. Depresión perinatal en tiempos del COVID-19: rol de las redes sociales en internet. Acta Med Peru. 2020;37(1):88-93. doi: https://doi.org/10.35663/amp.2020.371.913

18. Nan Y, Wei L, Qingling K, Zhi X, Shaoshuai W, Xingguang L, et al.Clinical features and obstetric and neonatal outcomes of pregnant patients with COVID-19 in Wuhan, China: a retrospective, single-centre, descriptive study. Lancet Infect Dis. 2020;20(5):559-64. doi: https://doi.org/10.1016/S1473-3099(20)30176-6

19. Livramento DVP, Backes MTS, Damiani PR, Castillo LDR, Backes DS, Simão AMS. Perceptions of pregnant women about prenatal care in primary health care. Rev Gaúcha Enferm. 2019;40:e20180211. doi: https://doi. org/10.1590/1983-1447.2019.20180211

20. David HMSL, Acioli S, Silva MRF, Bonetti OP, Passos H. Pandemics, crisis conjunctures, and professional practices: what is the role of nursing with regard to Covid-19? Rev Gaúcha Enferm. 2021;42(esp):e20190254. doi: https://doi. org/10.1590/1983-1447.2021.20190254 


\section{- Acknowledgment:}

We thank Universidade Federal da Fronteira Sul (UFFS) for the scientific initiation scholarships corresponding to public notice $279 / 2020$.

\section{- Authorship contribution:}

Conceptualization: Maíra Rossetto, Jeane B. Souza.

Methodology: Maíra Rossetto, Jeane B. Souza.

Writing - original draft: Maíra Rossetto, Jeane B.

Souza, Graciela S. Fonsêca, Vanessa V. Kerkhoff, Juliana Romanoski A. Moura.

Writing - review and editing: Maíra Rossetto, Jeane B. Souza, Graciela S. Fonsêca, Vanessa V. Kerkhoff, Juliana Romanoski A. Moura.

Supervision: Maíra Rossetto, Jeane B. Souza, Graciela S. Fonsêca.

Validation: Maíra Rossetto, Jeane B. Souza, Graciela S. Fonsêca.

Visualization: Maíra Rossetto, Jeane B. Souza, Graciela S. Fonsêca, Vanessa V. Kerkhoff, Juliana Romanoski A. Moura.

The authors declare that there is no conflict of interest.

\section{- Corresponding author:}

Maíra Rossetto

E-mail: maira.rossetto@uffs.edu.br

Associate editor:

Editor-in-chief:

Maria da Graça Oliveira Crossetti 